\title{
Research on Real Estate Wealth Effect under the Background of Double Cycle Based on VAR Model
}

\author{
Lina $\mathrm{Tao}^{1, \mathrm{a}}$ \\ Lina Tao (1986-) , female, lecture, research direction: urban economy, regional economy \\ School of Big Data and Artificial Intelligence Anhui Xinhua University Hefei,Anhui,China
}

\begin{abstract}
In order to cope with the complex and severe development situation at home and abroad, in May 2020, the Party Central Committee proposed to accelerate the formation of a new development pattern with the domestic cycle as the main body and the mutual promotion of the domestic and international double cycles. Among them, the consumption of Chinese residents is a "double cycle" key part of strategy. From the perspective of consumption structure and property structure, real estate is an important part of household property and an important consumer object in China and it has a decisive influence on the effect of internal circulation. By constructing a real estate wealth effect model, this paper adopted the impulse response function method based on the VAR model, studies the changes in real estate prices, residents' incomes, and residents' consumption. The results show that the three interact with each other. In the long run, real estate has a positive wealth effect, but in the short term, there is a negative wealth effect, and consumers' expectations of future housing prices will affect current consumption changes. In order to promote the domestic cycle, the author proposes to develop and improve the primary and secondary housing markets to ensure the liquidity of real estate, thereby stimulating consumption; guide residents to form healthy real estate price expectations, prevent large fluctuations in housing prices, and strictly stabilize consumption; the policy positioning of "no speculation" reduces the crowding-out effect of investment and speculative house purchases on residents' daily consumption, thereby increasing consumption.
\end{abstract}

\section{Introduction}

In response to the complex and severe development situation at home and abroad, in May 2020, the Party Central Committee proposed a "dual cycle" strategy to accelerate the formation of a new development pattern in which the domestic and international dual cycles are the mainstay and the domestic and international dual cycles promote each other. To achieve the "double cycle" goal, the key is to tap the potential of domestic market demand, accelerate the construction of a complete domestic demand system, open up all links of production, distribution, circulation, and consumption, and improve the efficiency of the domestic cycle. As an important industry related to the national economy and people's livelihood, real estate has a greater impact on the domestic economy and is an important part of the internal cycle. From the perspective of consumption structure and property structure, real estate is still an important part of household property and an important consumer object in China, and it has a decisive influence on the effect of internal circulation. On the property side, real estate accounts for a relatively large proportion of household property. According to the "China Household Wealth Survey Report 2019" released by the Economic Daily, the net value of urban households accounts for $71.35 \%$ of household wealth per capita, and the increase in net value of real estate accounts for $91 \%$ of the increase in household wealth per capita[1]. As urban households with higher net value of real estate gain more wealth accumulation from the substantial increase in net value of real estate, it is possible to increase consumer spending. On the consumer side, households are likely to have a crowding-out effect on consumption due to the purchase of houses. Judging from the quarterly data released by the People's Bank of China, in recent years, the balance of personal housing loans has shown a continuous growth trend. At the end of the fourth quarter of 2019, the balance of personal housing loans reached 30.07 trillion, a yearon-year increase of $16.7 \%$; the household sector leverage ratio increased from the end of $200817.9 \%$ rose to $55.8 \%$ at the end of 2019. At the same time, with the improvement of China 's urbanization level, the demand for housing purchase will further increase. As of the end of 2019, the urbanization rate of the permanent population in China is $60.60 \%$. According to the National Population Development Plan (2016-2030), the urbanization rate of the permanent population in China will reach $70 \%$ by 2030, even if urban residents are not considered There is still room for development in the real estate industry due to factors such as demand for improvement. In summary, 
under the current "dual cycle" background, studying the wealth effect of real estate is of great significance for promoting the domestic cycle, implementing the central government's strategy of "housing and not speculating", and achieving high-quality economic development.

\section{Model construction of real estate wealth effect}

The wealth effect of real estate [2] refers to the fact that real estate is an important part of household wealth under other conditions. Changes in real estate prices lead to changes in household wealth, which in turn will affect consumer spending.

According to Keynes's theory of permanent income, we should include residents' incomes when studying the influencing factors of consumption; according to Modigliani's life cycle theory, consumers smooth their wealth within their entire life cycle, According to the entire expected income of the whole life to arrange one's own life consumption, therefore, the total assets of households should be used as a variable that affects consumption. To simplify the analysis, we use real estate assets to represent household assets. In summary, we construct the following real estate consumption function model:

$$
C_{t}=b_{0}+b_{1} Y_{t}+b_{2} H_{t}+u_{t}
$$

Among them, $C_{t} 、 Y_{t} 、 H_{t}$ represent household consumption expenditure, household income, and real estate assets respectively, $u_{t}$ represent random disturbance items, $b_{0}$ represent necessary consumption, and $b_{1} 、 b_{2}$ represent household income and the marginal propensity to consume of real estate assets, respectively.

Considering that time series data may have heteroscedasticity, and in order to make the data change show a linear trend, we perform a natural logarithmic transformation on the selected variable series. Taking the logarithm on both sides of the equation will not change the linear characteristics of the data. That is to convert the model into the following form:

$$
L N C_{t}=b_{0}+b_{1} L N Y_{t}+b_{2} L N H_{t}+u_{t}
$$

\section{Selection of variables and data}

Since China's real estate market reform started in 1998, the author selected 88 periods of relevant data from the first quarter of 1998 to the fourth quarter of 2019 for analysis. Due to the availability of data, the author uses the retail sales of consumer goods $\mathrm{CO}_{t}$ (replace with $\mathrm{CO}_{t}$ below)to represent household consumption expenditure $C_{t}$ to measure changes in household consumption expenditure; since real estate wealth mainly exists in cities, in order to investigate the effect of urban residents' real estate wealth, the author uses the urban residents' precipitate disposable income $I N_{t}$ (replace with $I N_{t}$ below) is used to represent the residents' income index $Y_{t}$ to measure the income changes of urban residents[3]; since the real estate asset data of households is not easy to obtain, we use the average sales price of urban commercial housing $P R_{t}$ (replace with $P R_{t}$ below) to replace real estate assets $H_{t}$. After the above-mentioned index conversion, the new research index is brought into formula

(2) , and a new empirical analysis model is obtained, as shown in formula (3):

$$
L N C O_{t}=b_{0}+b_{1} \operatorname{LNIN}_{t}+b_{2} L_{N P R}+u
$$

\section{An Empirical Test of Real Estate Wealth Effect}

\section{1 data processing}

In order to better grasp the future development trend of the above variables, we used the $\mathrm{X}_{11}$ seasonal method to adjust the above variables seasonally before establishing the model, and the adjusted variable forms were transformed into $C O_{\text {sa }} I N_{\text {sa }}$,and $P R_{\text {sa }}$. We use the data of the above variables to draw a line chart as follows:

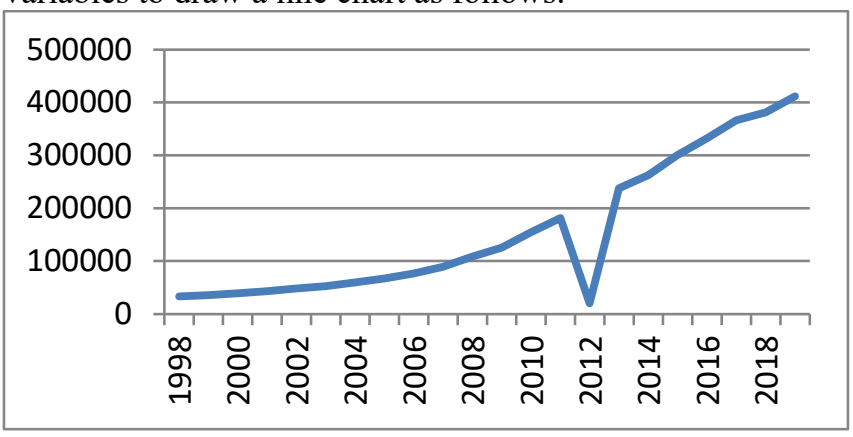

Figure 1. $\mathrm{CO}_{\text {sa }}$ Seasonal changes

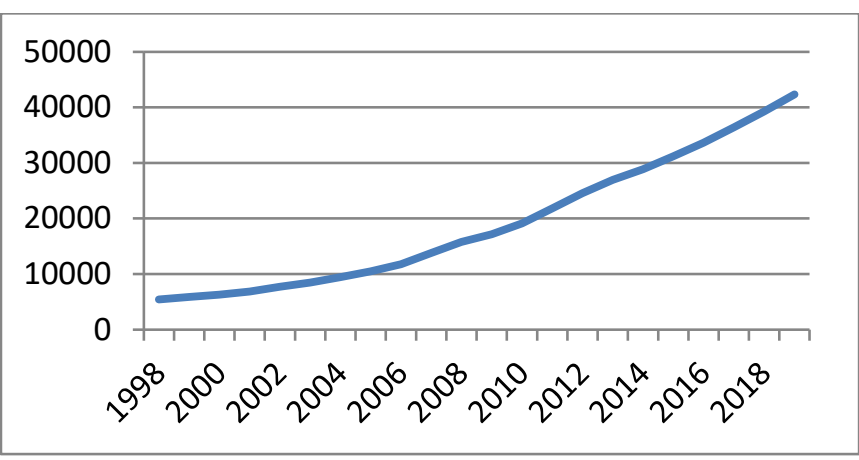

Figure 2. $I N_{\mathrm{sa}}$ Seasonal changes 


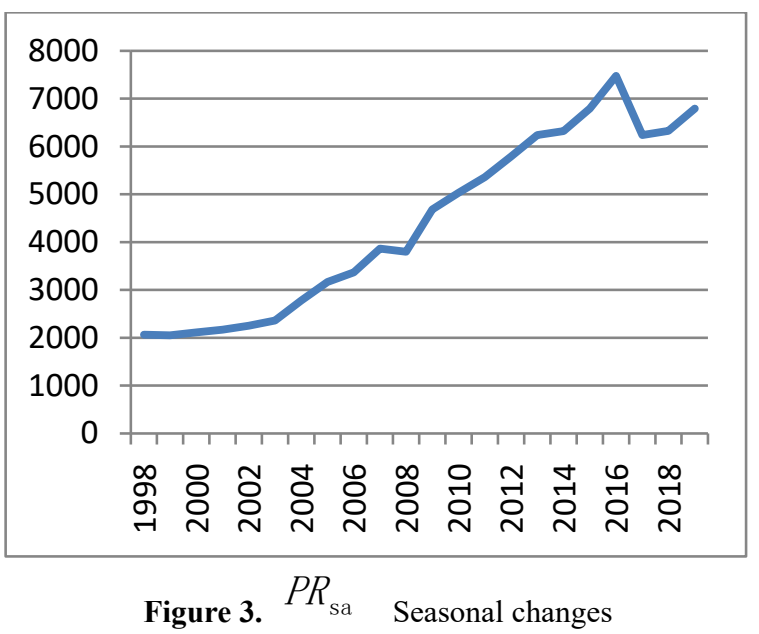

In order to eliminate the heteroscedasticity of the data, we perform logarithmic transformation, and the adjusted variable forms are respectively transformed into $L N C O_{\text {sa }}$, $L N I N_{\mathrm{sa}}, L N P R_{\mathrm{sa}}$, and the linear characteristics of the data will not be changed after the logarithmic transformation.

\subsection{Stationarity Test}

Before using time series data to establish an empirical analysis model, the stability of the data must be tested. If the data is not stable, then the empirical results may be false regression or wrong conclusions. When performing the ADF unit root test, it should be noted that: before the test, the form of the regression equation should be tested reasonably. The equation of ADF test has three forms: (1) If the graph of the sequence shows that it deviates from 0 and walks randomly, it indicates that the mean position of the sequence is 0 . At this time, the intercept term needs to be included in the regression equation; (2) If the sequence The graph shows that the fluctuation trend of the tested series changes with time, or shows a more obvious trend, then the regression equation at this time should include the time trend term; (3) In other cases, there is no intercept term and trend term. . Since the graph of the data sequence in this paper shows that it deviates from 0 and walks randomly, the intercept term should be included in the regression equation. Enter the data and get the following results, TableI.

Table I.Unit root test results of the original data

\begin{tabular}{|l|l|l|l|l|l|}
\hline Tested variable & $\begin{array}{l}\text { T-statistic value of } \\
\text { ADF test }\end{array}$ & $\begin{array}{l}\text { Statistics under the } \\
1 \% \text { inspection level }\end{array}$ & $\begin{array}{l}\text { Statistics under the } \\
5 \% \text { inspection level }\end{array}$ & $\begin{array}{l}\text { Statistics under the } \\
10 \% \text { inspection } \\
\text { level }\end{array}$ & conclusion \\
\hline$L N C O_{\text {sa }}$ & 2.227401 & -3.557472 & -2.916566 & -2.596116 & $\begin{array}{l}\text { Accept the null } \\
\text { hypothesis } \\
\text { with unit root }\end{array}$ \\
\hline$L N I N_{\mathrm{sa}}$ & 1.786299 & -3.555023 & -2.915522 & -2.595565 & Same as above \\
\hline$L N P R_{\mathrm{sa}}$ & 0.483980 & -3.555023 & -2.915522 & -2.595565 & Same as above \\
\hline
\end{tabular}

Through the above stationarity test, it is found that the original data series of all variables accept the null hypothesis at the $1 \%, 5 \%$, and $10 \%$ test levels, indicating that $\mathrm{CO}_{t}$, the per capita disposable income of urban residents, and the sales of urban commercial houses The average price series data all contain unit roots, which are a set of non-stationary time series data. Therefore, we tried to do unit root test on the first-order difference data of the above three variables and the results are as follows:

Table II. First-order difference data unit root test results

\begin{tabular}{|c|c|c|c|c|c|}
\hline Tested variable & $\begin{array}{l}\text { T-statistic value } \\
\text { of ADF test }\end{array}$ & $\begin{array}{l}\text { Statistics under the } \\
1 \% \text { inspection level }\end{array}$ & $\begin{array}{l}\text { Statistics under the } \\
5 \% \text { inspection level }\end{array}$ & $\begin{array}{l}\text { Statistics under the } \\
10 \% \text { inspection } \\
\text { level }\end{array}$ & conclusion \\
\hline$\Delta L N C O_{s a}$ & -10.19359 & -3.557472 & -2.916566 & -2.596116 & $\begin{array}{l}\text { Reject the null } \\
\text { hypothesis } \\
\text {, without unit root }\end{array}$ \\
\hline$\Delta L N I N_{s a}$ & -8.619118 & -3.557472 & -2.916566 & -2.596116 & Same as above \\
\hline$\Delta L N P R_{s a}$ & -8.209636 & -3.557472 & -2.916566 & -2.596116 & Same as above \\
\hline
\end{tabular}

Through the above-mentioned unit root test on the first-order difference of the time series data of retail sales of social consumer goods, per capita disposable income of urban residents, and the average price of urban commercial housing sales, we find that all the first-order difference data of the time series are stationary data. Therefore $\triangle L N C O_{s a}, \triangle L N I N_{s a}$ and $\triangle L N P R_{s a}$ are 
single integer sequences of the same order, and they are all I(1), and there may be a cointegration relationship between them.
In order to test the stationarity of the residual series, it is necessary to use the model estimation results to generate the residual series, and use eviews 9.0 calculation results to sort out the cointegration equation as follows:

\subsection{Cointegration Test}

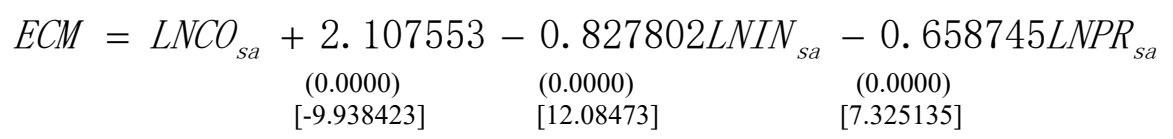

The coefficient of determination of the equation $R^{2}$ is 0.995973 , and the coefficient of determination after adjustment of the equation is 0.995821 , which is very close to 1 , indicating that the fitting effect of the model is good, and the parameters estimated by the equation are all very significant.

It can be seen from the co-integration equation that the per capita disposable income of urban residents is the main factor affecting consumption. Every change in the per capita disposable income of urban residents will cause a change in consumption in the same direction by one unit.
The influence of $P R_{t}$ on consumption is slightly inferior to the per capita disposable income of urban residents. Every change in $P R_{t}$ will cause a change of 0.658745 units in the same direction.

Use the above estimated equation to extract the residual sequence, and perform a unit root test on the residual sequence. The selected equation form has no trend term and no intercept term. The test results are as follows:

Table III. Unit root test result of residual data

\begin{tabular}{|l|l|l|l|l|l|}
\hline Tested variable & $\begin{array}{l}\text { T-statistic value } \\
\text { of ADF test }\end{array}$ & $\begin{array}{l}\text { Statistics under } \\
\text { the } 1 \% \text { inspection } \\
\text { level }\end{array}$ & $\begin{array}{l}\text { Statistics under } \\
\text { the 5\% inspection } \\
\text { level }\end{array}$ & $\begin{array}{l}\text { Statistics under } \\
\text { the } \\
\text { inspection level }\end{array}$ & conclusion \\
\hline ECM & -5.140447 & -2.607686 & -1.946878 & -1.612999 & Reject the null \\
& & & & & hypothesis \\
\end{tabular}

It can be seen from Table III that the $\mathrm{T}$ statistic of the residual unit root test is -5.140447 , and the corresponding probability value $\mathrm{P}=0.0000$, which is less than the test levels of $1 \%, 5 \%$, and $10 \%$. Therefore, it is rejected that the residual sequence has a unit root the original hypothesis of is that the residual sequence is considered to be stationary. According to the definition of the cointegration relationship, it can be considered that there is a cointegration relationship among the sequence $L N C O_{\text {sa }}$, the sequence $L N I N_{\mathrm{sa}}$, and the sequence $L N P R_{\text {sa }}$, and then the error correction model is estimated.

$$
\begin{array}{ccc}
\Delta L N C O_{s a}= & 0.041566+ & 0.230069 \Delta L N I N_{s a} \\
& (0.0009) & (0.0168) \\
{[3.524175]} & {[2.471915]}
\end{array}
$$

The F-statistic value of the model estimation result is 6.087882 , the corresponding probability value $\mathrm{P}$ is 0.001271 , and the coefficient of determination is 0.863683 , which shows that the model estimation is significant as a whole.

Using the estimated model, we can analyze the shortterm changes in consumption expenditure: First, $P R_{t}$ is the main factor affecting consumption. Every change in $P R_{t}$ will cause a change of 0.703683 in the opposite direction. Unit; second, the influence of $I N_{t}$ on consumption is second to that of urban commercial

\subsection{Error correction model}

The results of the co-integration test show that $C O_{t}$, the per capita disposable income $I N_{t}$ of urban residents, and $P R_{t}$ have an obvious equilibrium relationship in the long run, but in the short term, the equilibrium relationship is not clear, so it can Use the error correction model to consider. According to the estimation results of the error correction model calculated by eviews9.0, the error correction model is as follows:

$$
\begin{array}{lc}
-0.703683 \Delta L^{2} N P R_{s a}- & 0.515647 E C M(-1) \\
(0.0004) & (0.0991) \\
{[-3.821791]} & {[-1.679950]}
\end{array}
$$

housing sales. Every change in $I N_{t}$ will cause consumption to change in the same direction by 0.230069 units; third, due to the previous In order to maintain the long-term equilibrium relationship between actual consumption expenditure and actual disposable income, the consumption expenditure of the previous period will be adjusted at a rate of -0.515647 (that is, the estimated value of the coefficient of the error correction term) in the current period. Adjust the disequilibrium state between expenditure and income and house prices to adjust it to a long-term equilibrium state. 


\subsection{Granger Causality Test}

Granger causality test is mainly to verify the existence of real estate wealth effect. If $P R_{t}$ is the Granger reason for $C O_{t}$, it indicates that changes in $P R_{t}$ will cause changes in the retail sales of social consumer goods, and that changes in housing prices will affect the changes in
Granger reason for $\mathrm{CO}_{t}$, the results obtained from the above empirical test are questionable.

Since the Granger causality test relies on the lag length in the test regression model, Table 4 provides several lag length $\mathrm{F}$ test results. The results of Granger causality test of $L N C O_{\text {sa and }} L N P R_{\text {sa }}$ are shown in Table IV: consumer spending. Conversely, if $P R_{t}$ is not the

Table IV. Granger causality test results

\begin{tabular}{|c|c|c|c|c|}
\hline Null hypothesis & Lag length & F statistics & P value & conclusion \\
\hline$P R_{t}$ is not the Granger reason for $C O_{t}$ & 2 & 3.80077 & 0.0294 & $\begin{array}{c}\text { Reject the null } \\
\text { hypothesis }\end{array}$ \\
\hline$C O_{t}$ is not the Granger reason for $P R_{t}$ & 2 & 4.55339 & 0.0155 & Same as above \\
\hline$P R_{t}$ is not the Granger reason for $C O_{t}$ & 3 & 7.31613 & 0.0004 & Same as above \\
\hline$C O_{t}$ is not the Granger reason for $P R_{t}$ & 3 & 2.73216 & 0.0140 & Same as above \\
\hline$P R_{t}$ is not the Granger reason for $C O_{t}$ & 4 & 3.54326 & 1.92826 & 0.1235 \\
\hline$C O_{t}$ is not the Granger reason for $P R_{t}$ & 4 & Same as above \\
\hline
\end{tabular}

According to the analysis results in Table IV, from lag length 2 to lag length $4, P R_{t}$ is the Granger reason for the retail sales of social consumer goods; for lag lengths 2 and 3, the retail sales of social consumer goods is the average price of urban commercial housing sales Granger reason: For lag length 4 , the test $\mathrm{F}$ statistic is not significant at the test level of $10 \%$, so the null hypothesis cannot be rejected. According to the results of the analysis, it can be roughly considered that $P R_{t}$ is the Granger cause of the retail sales of social consumer goods, and the retail sales of social consumer goods are the Granger cause of $P R_{t}$. There is a two-way causal relationship[4].

\section{Main conclusions and policy recommendations}

\subsection{Main conclusion}

1). The three variables, retail sales of social consumer goods, per capita disposable income of urban residents, and average sales price of urban commercial housing, are non-stationary time series, but they have a long-term equilibrium relationship in the long run. This shows that real estate prices, urban residents' incomes, and consumption interact with each other.

2 ). In the long run, the per capita disposable income of urban residents is the main factor that promotes consumption. $P R_{t}$ has less influence on consumption than the per capita disposable income of urban residents. This indicates that changes in real estate prices will stimulate consumption in the same direction At the same time, per capita income is also an important factor affecting consumption. There is a positive wealth effect in the real estate market, that is, the wealth effect of Chinese residents' real estate is relatively significant, and the real increase in real estate wealth is indeed conducive to the growth of consumption. The result of Granger causality test also proves the existence of the above-mentioned relationship. Therefore, when real estate prices maintain an upward trend, residents will increase consumer spending.

3). In the short term, both $P R_{t}$ and the per capita disposable income of urban residents affect consumption. $P R_{t}$ is the main factor affecting consumption. Every change in $P R_{t}$ will cause consumption to change in the opposite direction. 0.703683 units. The influence of urban residents' per capita disposable income on consumption is inferior to that of urban commercial housing sales. Every change in urban residents' per capita disposable income will cause consumption to change in the same direction by 0.230069 units. This shows that in the short term, the effect of real estate wealth is negative, and the increase in real estate prices has a restraining effect on consumption. It also proves that the Party Central Committee's decision not to use real estate as a short-term economic stimulus is correct.

4). According to the error correction model test, it is shown that due to the influence of the previous period's consumption expenditure deviating from the long-term equilibrium relationship, in order to maintain the longterm equilibrium relationship between actual consumption expenditure, real estate prices, and actual disposable income, the current period will be at a rate of -0.515647 (That is, the estimated value of the coefficient of the error correction term) adjust the disequilibrium state between the previous period's consumption expenditure, income, 
and house price, and adjust it to a long-term equilibrium state, which shows that consumers' expectations of future house prices will affect Changes in current consumption.

5). In the long-term and short-term, changes in real estate prices and changes in per capita disposable income have different effects on consumption. In the long run, every unit change in the per capita disposable income of urban residents will cause a consumption change of 0.823628 units in the same direction, while a change in $P R_{t}$ in the same dire a consumption change of 0.692931 units in the same direction, that is, urban commercial housing. The influence of average sales price on consumption is inferior to the per capita disposable income of urban residents. On the contrary, in the short term, the influence of per capita disposable income of urban residents on consumption is inferior to the average price of urban commercial housing.

\subsection{Policy recommendations}

1). Develop and improve the primary and secondary housing markets. Due to the significant wealth effect in the real estate market, we should protect the property rights of residential houses, improve the order of real estate transactions and leasing markets, ensure the liquidity of real estate, and promote the conversion of real estate from real estate to "movable property" for households, thereby stimulating consumption.

2). Guide residents to form healthy real estate price expectations. Advocate a positive concept of housing consumption, curb speculative housing demand, ensure the stable, healthy and sustainable development of the real estate market, and prevent large ups and downs in housing prices. It is necessary to prevent residents from overconfidence and irrational consumption due to temporary increases in housing prices; prevent residents from having pessimistic expectations due to the temporary fall in house prices and showing cautious consumption behavior. Government should accelerate the establishment and improvement of top-level designs such as housing for the elderly, to help residents smooth the wealth of real estate to life, so that their consumption utility during the entire life cycle can reach the best.

3). Adhere to the policy positioning of "housing, not speculating". Since real estate has the dual attributes of investment products and consumer goods, under the background of the limited investment products and investment channels of Chinese residents, the real estate industry continues to prosper, which easily triggers the transfer of industrial funds, which results in hollowing out of the industry and is not conducive to the sustained and healthy development of the economy. Therefore, we must curb unreasonable housing demand, provide residents with a wealth of investment products and investment channels, and strictly control credit channels other than consumer housing loans to reduce the crowding-out effect of investment and speculative housing purchases on residents' daily consumption. Increase wealth effect.

\section{Acknowledgment}

Fund project : Software engineering professional teaching team(2019jxtd119).

\section{References}

1. https://xw.qq.com/cmsid/20191030A07NL900?f=ne wdc.

2. Han Jin, Hu Weizhong. "An empirical study on housing price volatility and retail sales growth: Granger causality test to statistical data of Hangzhou during 2005 to 2009", 2010 2nd IEEE International Conference on Information Management and Engineering, 2010.

3. Guan Yu, Jiao Fang-Yi, Zhu Hong-Zhang, RenJiaSong. "Real Estate Prices and Consumption in China: 1998-2011", Information Technology Journal, 2013.

4. Lifang Huang, Lin Wang. "Study on the Relationship between the Development of Commercial Real Estate and the Total Retail Sales of Consumer Goods: From ChongqingCase", ICCREM 2017.2017. 